\title{
Recommendations for perinatal care in the context of the COVID-19 pandemic
}

Maysa Arlany de Oliveira 1

https://orcid.org/0000-0002-4022-3554

Natácia Élem Felix Silva 2

(iD) https://orcid.org/0000-0003-0503-6603

Juliana de Castro Nunes Pereira 3

https://orcid.org/0000-0001-6831-1639

Mayara Amanda de Oliveira 4

https://orcid.org/0000-0002-3383-2175

Suzana Lins da Silva 5

https://orcid.org/0000-0001-9783-0737
Maria de Fátima Costa Caminha 6

(iD) https://orcid.org/0000-0003-0653-5324

Weslla Karla Albuquerque Silva de Paula 7

(iD) https://orcid.org/0000-0002-0237-2663

Glauberto da Silva Quirino 8

(iD) https://orcid.org/0000-0001-5488-7071

Dayanne Rakelly de Oliveira 9

iD https://orcid.org/0000-0003-2911-141X

Rachel de Sá Barreto Luna Callou Cruz 10

(iD) https://orcid.org/0000-0002-4596-313X

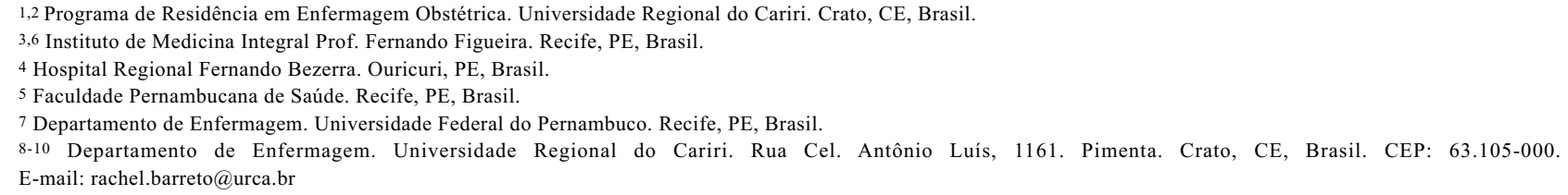

\section{Abstract}

Objectives: to present scientific recommendations for perinatal care in the context of the COVID-19 pandemic.

Methods: a narrative review was carried out between March and September in 2020 from BIREME, the Scientific Electronic Library Online and the Virtual Health Library databases, based on the descriptors: "Perinatal Care"; "Coronavirus"; "Coronavirus Infection"; "Obstetrics" and "Newborns". The information was grouped into four categories, namely, prenatal care; labor and birthcare; care for puerperal women and the newborn.

Results: 14 publications were found, 9 scientific articles and 5 technical standards pursuant to the Ministry of Health in Brazil. In the first category, generally, it is recommended that prenatal consultations should be continued, if necessary, by means of telemedicine; hospitalization of positive pregnant women in case symptoms are severe and considering pregnant women's clinical and emotional aspects. In the second, screening and testing on suspected cases, discouraging skin-to-skin contact and breastfeeding in the first hour of life. In the third, change the arrangement of beds in shared accommodations and have early discharge. In the fourth category, it is also recommended late clamping of the umbilical cord and observe differences in laboratorial testing of asymptomatic neonates.

Conclusions: scientific evidence based on studies with methodological designs and more robust analyzes are necessary to guide perinatal care in the context of the harm-free COVID19 pandemic.

Key words Perinatal care, Prenatal care, Coronavirus, Coronavirus infection, Obstetrics, Newborn 


\section{Introduction}

COVID-19 is a disease caused by SARS-CoV-2, belonging to the family of coronavirus, which triggers respiratory and more rarely intestinal infections. Discovered in 2019 in the province of Wuhan, China, and with rapid transmission, in a few months the new virus was installed and became a state of pandemic, which was declared by the World Health Organization (WHO) in March 2020. In the beginning it was considered a risk group, elderly people, over 59 years of age and carriers of comorbidities related to the immune system, such as hypertension, diabetes mellitus, respiratory tract diseases, pathologies associated with immune deficit, and among others. 1

The transmission occurs through contact from person to person or on contaminated surfaces by droplets or secretions. The incubation period can vary from 0 to 14 days with an estimated average of 5 to 6 days for the onset of the symptoms. The individuals present asymptomatic, mild or severe symptoms, whereas the most common symptoms are: coughing, sudden onset fever $\left(>37.8^{\circ} \mathrm{C}\right)$, asthenia, malaise, myalgia, runny nose or dyspnea $\left(\mathrm{StO}_{2}<95 \%\right)$. Gastrointestinal symptoms such as diarrhea, nausea and vomiting may also be present. For laboratory diagnosis, RT-PCR is considered the gold standard, associated with imaging exams such as computed tomography, chest radiography or pulmonary ultrasonography. 1,2

In Brazil, in April 2020, the Ministry of Health (MH) included pregnant women at any gestational age and women in the puerperal period who suffered fetal loss or abortion up to fifteen days as belonging to this risk group. ${ }^{1}$ The presence of pregnancy does not increase the risk of severe clinical presentation of the disease.1,3 According to the Royal College of Obstetricians and Gynaecologists, pregnant black women who are overweight $\left(\mathrm{BMI}>25 \mathrm{~kg} / \mathrm{m}^{2}\right)$, who have pre-existing comorbidities and are over 35 years of age, have a greater chance of developing severe conditions when affected by coronavirus. ${ }^{3}$

As for the symptoms, some studies show that they are similar to the symptoms presented in nonpregnant women.2,3 According to a study published in the American College of Obstetricians and Gynecologists compared a group of pregnant women with non-pregnant women, it was concluded that pregnant women had greater chances of developing severe conditions of the disease, as well as requiring greater ventilatory support; the same association was not observed in relation to mortality. 4

There are limitations in understanding the rela- tion between pregnancy and COVID-19, because, so far, published studies contemplate women in the period between the second and third trimester of pregnancy. However, it is known that there has been no increase in the number of abortions or malformations identified by ultrasonography during the prenatal follow-up. ${ }^{5}$

Given the essentiality of obstetric and neonatal care services in the midst of the pandemic scenario, as well as the need for professionals involved in prenatal and perinatal care to be updated. This study aimed to present the scientific recommendations for perinatal care in the context of the COVID-19 pandemic.

\section{Methods}

It is a narrative review that analyzed scientific articles, guidelines, protocols and official documents from the MS.

The articles related to the subject were searched in the journal portal of the Coordenação de Aperfeiçoamento de Pessoal de Nivel Superior (CAPES - Coordination for the Improvement of Higher Education Personnel) in the databases of Latin American Center and the Caribbean on Health Sciences Information (BIREME), Scientific Electronic Library Online (SciELO), Biblioteca Virtual em Saúde (BVS) (Virtual Health Library) and related sites from March to September 2020. The following descriptors were used: "perinatal care", "coronavirus", "coronavirus infection", "obstetrics" and "newborn".

After the search stage, a filter was applied for temporal delimitation from December 2019 to August 2020. Afterwards, the titles and abstracts of the identified articles were read, applying the full text criteria available and articles that mentioned about the scientific recommendations for perinatal care in the context of the COVID-19 pandemic. No language limits were applied during the searches. Articles that did not answer the guiding question were excluded.

There were 9 articles left and the Technical Notes of numbers $6,7,9,10$ and 14, 6-10 these were the $\mathrm{MH}$ reference documents in the context of the COVID-19 pandemic considered essential for the understanding of the phenomenon investigated, totaling a sample of 14 publications that constituted the analytical corpus of this study.

In the analysis, we used the data reduction method that involved thorough reading and techniques to classify into subgroups of primary sources, according to the approach and methodological 
aspects. ${ }^{11}$ This process allowed to organize the data in a logical structure, simplifying, summarizing, abstracting and systematically comparing the results from primary studies and documents on the object studied, 11 facilitating the interpretative analysis and presentation of the review.

Tables with descriptive summaries of the selected documents were prepared to make the recommendations objective and facilitate access to the information. They were also presented and discussed in conceptual categories: prenatal care, labor and birth care, puerperal care, and newborn care.

\section{Results}

The articles analyzed were published by researchers from the United States $(n=2)$ and Brazil $(n=2)$, followed by studies published in China $(n=1)$, France $(n=1)$, Canada $(n=1)$, England $(n=1)$ and Spain $(n=1)$. All of them were published in 2020 , in English, in journals in the area of Obstetrics and Gynecology and pathology/virology/physiopathology. The methodological guidelines used were: case studies $(n=1)$, cross-sectional $(n=2)$, cohorts $(n=3)$, bibliographic reviews $(n=2)$ and systematic review with meta-analysis $(\mathrm{n}=1)$.

The summary of the main recommendations published in the MH Technical Standards in the context of the COVID-19 pandemic is presented (Table 1)

The researches describe some of the necessary changes during the care routine of the mother-baby binomial, from the prenatal consultations, the admission to the hospital service, the puerperium and the care of the newborn. The recommendations tend to modify the standard of care of the service according to the clinical frame presented by the pregnant woman/puerperal and neonate, if asymptomatic, suspicious or confirmed (Table 2).

\section{Discussion}

Perinatal care involves the integral care of the mother-baby diode, which includes the entire gestational cycle, labor, birth, puerperium, and newborn care. It is important that it involves a multidisciplinary team, promoting satisfactory and quality care. ${ }^{8}$ The main guidelines and recommendations within the COVID-19 context have been listed and are discussed in the following categories.

\section{Prenatal care}

Prenatal care aims to ensure maternal-fetal well- being and safety, through periodic consultations, qualified listening, physical examination, requests and evaluations of complementary exams, in order to mitigate or diagnose early health risks. The $\mathrm{MH}$ recommends the permanence of face-to-face consultations, as long as the pregnant woman does not present any symptom related to COVID-19.6,7 In case of flu syndrome, the professional should postpone the consultation for 14 days, performing the teleconsultation and rescheduling the face-to-face procedures in a timely manner and with an appointment, avoiding agglomerations or longer waiting hours at the service. $6,7,12$

It is recommended that check-up examinations should be requested and evaluated, and that they should coincide with face-to-face consultations and the application of vaccination doses, in order to ease the patient's circulation. 3,6,7,12 It is important to emphasize that women's autonomy and protagonism in care are essential, so that they are oriented to identify warning signs during pregnancy, and to address themselves in a timely manner to obstetric and neonatal referral hospital care. $4,6,7$

For pregnant women who are positive for SARS$\mathrm{CoV}-2$, fetal surveillance needs to be doubled, since other endemic diseases are caused by the coronavirus, such as - Severe Acute Respiratory Syndrome (SARS) and Middle Eastern Respiratory Syndrome (MERS) - have been shown to cause, in fetuses of positive mothers, intrauterine growth restriction(IUGR). There are still no studies that prove the same characteristic coming from the etiologic agent of COVID-19.3,6,7 However, the number of preterm births in infected pregnant women has been increasing, which justifies the recommendation of administering corticoids between 24 and 34 weeks of pregnancy in cases of mothers with a clinical frame of potential aggravation. ${ }^{2,5}$

As for vertical transmission, studies describe that it is possible, since after tests for identifying SARSCoV-2 in a neonatal biological sample, a positive result was obtained.3,13 A case report study conducted in France described the presence of SARS-CoV-2 in all laboratory samples, from amniotic fluid (AF), collected before the rupture of the membranes, placental blood and the newborn's blood collected in the first 12 hours of life after cesarean section from a mother positive for COVID19. Inflammatory signs were observed in the placenta characteristic of infection and inflammatory cells in the cerebrospinal fluid of the newborn. 14 In cases of SARS and MERS, no vertical transmission was identified.5-7

According to the $\mathrm{MH}$, pregnant women with 
Table 1

Summary of the main recommendations published in the Technical Standard Norms from the Ministry of Health in the context of the COVID-19 pandemic.

Technical Norm Date of Publication Subject Main Recommendations

\begin{tabular}{lll}
\hline Number 6/2020- & $03 / 23 / 2020$ & $\begin{array}{l}\text { Care for Pregnant Women in } \\
\text { the Context of SARS-CoV-2 }\end{array}$ \\
COSMU/CGCIVI/DA & & Infection \\
PES/SAPS/MS & &
\end{tabular}

Protocol on the diagnosis of COVID-19 for pregnant women should be the same as of the general adult population; permanence of presential prenatal consultations of asymptomatic pregnant women; there is still no scientific confirmation that vertical transmission occurs; there is no evidence of teratogenesis morphological ultrasonography in the second trimester

Number 7/2020-

COSMU/CGCIVI/DA

$04 / 08 / 2020$

PES/SAPS/MS

Number 9/2020-

COSMU/CGCIVI/DA

PES/SAPS/MS

Number 10/2020-

COCAM/CGCIVI/DA

PES/SAPS/MS

Number 14/2020

COCAM/CGCIVI/DA

PES/SAPS/MS

$04 / 10 / 2020$

$03 / 23 / 2020$

$08 / 05 / 2020$
Care for pregnant women in the context of COVID-19 infection caused by Coronavirus (SARS-CoV-2).

Recommendations for labor, delivery, and puerperium during the COVID-19 pandemic.

Care for the NB's health in the context of infection by the new coronavirus (SARS

(oV-2).

Care for the NB's health in the context of infection by the New Coronavirus (SARS-. CoV-2). 2
It presents the same recommendations described in Technical Norm number 6. However, the text "There is still no scientific confirmation that vertical transmission of SARS-CoV-2 occurs. Among the cases reported so far, it is not known whether transmission to the fetus/newborn (NB) occurred before or after birth.15,16 Other reported cases of positive pregnant women for SARS-CoV-2 presented virus-free neonates, including in cord blood and placenta. ${ }^{3}$

Admission of pregnant women and suspected or positive companions for COVID-19; multi-professional team; place of delivery; recommendations for postpartum.

No consolidated evidence of vertical transmission; guidelines for delivery room conducts; guidelines for joint housing; guidelines for neonatal unit; recommendations related to hospital discharge.

Minimum distance between the mother's bed and the newborn's crib of 1 meter and preferably 2 meters; for the protection of the newborn in the joint housing, the use of incubators instead of cradles may be considered.

Search deadline: 08/31/2020. COSMU = Women's Health Coordination; CGCIVI = General Coordination of Life Cycles; DAPES = Department of Strategic Programmatic Actions; SAPS $=$ Secretary of Primary Health Care; MS = Ministry of Health; COCAM = Coordination of Child Health and Breastfeeding. 


\begin{tabular}{llll}
\hline Gestational period $\quad$ Labor and delivery & Puerperal period
\end{tabular}

Permanence of face-to-face prenatal consultation.6,7,12

Professionals should employ teleconference and videoconference whenever possible and consider which appointments can be conducted remotely.3,12

Request for laboratory tests and imaging when necessary.3,6,7,12

Postpone prenatal appointment for pregnant women with influenza syndrome. 6,7

Hospitalization of positive pregnant women in case of severe symptoms. 17,18

All pregnant women and their companions should be screened for suspected or confirmed cases of

COVID-19 prior to their admission to

hospital service. 9,12

Pregnant women admitted with suspected COVID-19 or who developed symptoms during admission should be prioritized for testing. ${ }^{19}$

Appropriate team with all recommended IPE's.3,4,9,12, 19

Offer non-pharmacological methods for pain relief.2-9

Discourage home birth, NBC in cases Discourage outside visits for the mother and

of suspect or positive pregnant the newborn.9,10 women for SARS-CoV-2.8,12 from the NB's cradle. $3,4,9,10,19$

Stimulate exclusive breastfeeding, even for mothers positive of COVID-19, following biosafety protocol.9,10,20
Asymptomatic or mild symptomatic puerperal should remain in the join housing. $2,9,10$

Bed with a minimum distance of two meters
Umbilical cord clamping should be performed in a timely manner, between 1 and 3 minutes. $2-4,9,10,12,20$
It is not indicated laboratory screening to investigate SARS-CoV-2 in asymptomatic NB, whose mother has a suspect or confirmed diagnosis of COVID-19.9,10

Perform RT-PCR on all newborns with suspected or confirmed mothers to COVID-19, regardless of signs of infection in the NB. ${ }^{2}$

Transportation for the newborn to any place in the hospital should be carried out in his/her own incubator transport.21 


Gestational period Labor and delivery Puerperal period N Neonatal period

Special attention should be made to uterine height measurements and fetal parameters. $2,3,4,12$

Special attention to the pregnant woman's psychological aspects. 22,23
Discourage skin to skin contact and breastfeeding during the golden hour in symptomatic or having contact with patients of people with influenza syndrome or SARS-CoV-2 infection.. $3,4,9,10,20$

Indication for cesarean section in case of maternal or fetal clinical severity.2,3,4
Puerperal in good condition should be released within 24 hours. 8,18

Early discharge from hospital, 24 hours for vaginal delivery and 48 hours for cesarean section. 2,12

Patients with COVID-19 may be discharged from the health care unit whenever there is a clinical indication. 19

After discharge from hospital it is suggested that the maintenance of elective follow-up appointments by the Basic Care team should be considered a therapeutic opportunity through a routine vaccination, growth and development surveillance, and guidance for the family.9,10
Carry out immediate care for the newborn in a room separate from the mother if it is not possible to maintain a distance of at least 2 meters between the mother and the resuscitation table.21

Early discharge from hospital, in 24 hours if it is vagina delivery and 48 hours if it is cesarean delivery. 2,12

NB is in good condition, hospital discharge within 24 hours. 8 
severe symptoms, it is necessary to be hospitalized in the isolation sector, in a reference service, for rigorous maternal (blood pressure, heart rate, respiratory rate, $\mathrm{O}_{2}$ saturation), and fetal (fetal movements, heartbeat, ultrasonography and cardiotocography) monitoring. ${ }^{8}$ After recovery, obstetric ultrasonography is recommended between 2 to 4 weeks post-cure, in order to evaluate fetal growth and AF levels. 5

In the care of pregnant women with COVID-19, pregnancy termination is not indicated in positive cases, except for those in which there is maternal risk or fetal suffering, with real indication for performing a cesarean section. 8,12

A study conducted in China with 4124 pregnant women in the third quarter, analyzed these women's mental health. The symptoms presented in the preand post period of the COVID-19 pandemic announcement were compared, the group evaluated after the onset of the pandemic was more likely to develop depressive symptoms and thoughts of selfmutilation when compared to the other group. $23 \mathrm{~A}$ survey conducted in Canada of 1754 pregnant women between 4 and 41 weeks of gestation, were analyzed and showed clinically significant levels of depressive symptoms and increased anxiety. 22

\section{Labor and birth care}

The Centers for Diseases Control and Prevention (CDC) in the United States advises that units providing services for pregnant women and newborns should adapt its physical structure so that the transmission of the virus is prevented. Sectors such as reception, screening and isolation wards, intended for patients with suspicion, or confirmed for COVID-19, must be identified and separated from the other wards. 19 Professionals must be wearing personal protective equipment (PPE), provided by the institution. $3,4,8,19$

According to some institutional protocols it is important that the admission criteria be well defined and that all pregnant women admitted to the service be tested for COVID-19, even if they do not present symptoms of the disease, considering that there are asymptomatic cases. ${ }^{17,18}$ However, it is advised to test asymptomatic pregnant women which is a medical and institutional discretion. 22 Pregnant women who do not show signs of active PT, hospitalization is recommended in case of SARS or influenza syndrome associated with decompensated comorbidities, obstetric indications of hospitalization or who present social vulnerability, or difficulty in accessing the institution. 17,18
During labor and delivery care, it is advised that a few people should be remained, and that the presence of the woman's companion of choice is guaranteed, as long as the companion responds to preestablished criteria such as: not being a suspect or confirmed case and not having had direct contact with any confirmed case in the last 15 days of admission; not having a chronic condition; being between 18 and 59 years old; and have the availability to stay during the whole hospitalization procedure, following the norms of the service, such as full use of a mask, and hand washing periodically. 2,8,19

In suspect patients or patients with confirmed diagnosis, it is recommended that the surveillance of maternal-fetal vital signs be more regular, in order to identify early signs of maternal and/or fetal decompensation, since studies have shown higher rates of fetal distress and prematurity in mothers with SARSCoV-2.3,4,8,12,17 In accordance with these findings, a British study presented in its results the outcomes of hospitalization of patients positive for COVID-19, $27 \%$ were premature births, among which $47 \%$ iatrogenic due to maternal impairment and $15 \%$ related to fetal suffering. Of the term newborn, $10 \%$ needed a neonatal intensive care unit, and $2.5 \%$ were diagnosed with the virus in the first 12 hours of life. 24

Regarding non-pharmacological methods for pain relief, the indication remains that they should be offered to women in labor, as long as they are individuals. $2,3,8$ Suspected or having SARS-CoV-2 should not be assisted in normal delivery centers (NDC) or at home, and it is recommended that they should occur in a reference service, due to the possibility of eventual complications.2-4,8,12 Water birth is contraindicated, since it has already been observed the presence of the virus in feces of contaminated patients. $3,4,8$

The decision to terminate pregnancy should be made based on three aspects: general condition of the patient, gestational age and fetal vitality. 5 The birth route should be indicated according to each case, considering the best for the mother-baby binomial.3,4,5 However, vaginal delivery remains the best route for birth, even with the initial evidence of vertical transmission via placenta. ${ }^{3}$ This information corroborates the results of a Spanish research that evaluated maternal and neonatal outcomes associated with the type of delivery in women positive for SARS-CoV-2 and demonstrated that none of those who performed the vaginal delivery were severe, while $5(13.5 \%)$ of those who underwent cesarean section required admission to the intensive care unit. 25

Intrapartum interventions such as episiotomy or 
operative vaginal delivery aimed to reduce fetal time in the vaginal canal are contraindicated and should only be performed with real indication.3,4,17 All protocols and guidelines are unanimous in the orientation to perform timely cord clamping in normal and operative deliveries in the following cases: from 1 to 3 minutes in NB births with GA>34 weeks, from 30 to 60 seconds, in NBs with $\mathrm{GA}<34$ weeks, provided they are active and presenting good tone and crying. In cases where the placenta is not intact or where the newborn does not present crying and/or tonus, immediate clamping is recommended for continuity of care. $2-4,6,7,17,21$

As for the "golden hour", some evidence points out that there should not be skin-to-skin contact with the mother in the first hour of life, nor breastfeeding of mothers suspected or positive for SARS-Cov-2, because care in this period is mainly focused on the prevention of infection of the newborn after birth. 3,21 For the American College, the decision to put the newborn in contact with the mother after birth should be taken according to each case, together with the patient, provided that she is previously informed of possible risks. 4

\section{Care for the puerperal}

Care for clinically stable mothers should remain according to the routine of the service. For puerperal with clinical suspicion or confirmed for COVID-19, it is advised that there is a private space in the joint housing for their accommodation next to the NB, if stable. 9,10 For this regard, a minimum distance between the mother's bed and the newborn's cradle should be one meter or preferably two meters away, the contact of both should berestricted only at the moment of breastfeeding. The mother should wear a surgical mask provided by the service at all times of lactation and should sanitize her hands before and after breastfeeding. ${ }^{2-4,9,10,20}$

The best nutrition for the NB is still breast milk, which should be stimulated by professionals, and there is no evidence of mothers with COVID-19 can transmit the virus via milk. Breastfeeding is a woman's exclusive choice in accordance with the family support and the professionals who assist her. 4,26

In case the puerperal has recently been admitted to the ICU and wish to breastfeed, the milk must be extracted and offered to the infant. In cases of maternal severity, the team must make sure that there is no breast engorgement and can milk the breasts if necessary. 2 The Sociedade Brasileira de Pediatria (Brazilian Society of Pediatrics) makes it explicit the contraindication of milk donation by mothers affected with SARS-CoV-2.20

According to $\mathrm{MH}$ recommendations, it is important to suspend hospital visits and reduce the number of people in the service. It is also recommended that in case the puerperal and the clinically stable neonate, the companion should be excused, except for underage mothers or in case of real necessity. $8-10$ It is necessary that hospital discharge occurs as soon as possible, considering maternal and neonatal wellbeing, carrying out guidelines about home care, and emphasizing the need for family support. $2,4,9,10,12$

For women who have suffered abortions or fetal loss, the professional should analyze each case. It is important to mitigate the risks during the care period and, in case of asymptomatic women with retained abortion, expectant conduct is advisable, as well as early discharge. 2 According to hospital protocol, for embryo/fetal loss and placenta of women positive for COVID-19, the measure is valid for all concepts weighing less than 500 grams. ${ }^{18}$

\section{Newborn care}

The care given to the newborn seeks non-infection after birth.9,10,21 Studies focusing on this population group are still so far limited: it is that children under one year of age may have a higher risk of severe COVID-19 disease when compared to children of other age groups. 27 Another possibility is that the NB is exposed to the virus at birth via vaginal, considering the possibility of the presence of SARS$\mathrm{CoV}-2$ in the urine and feces of contaminated patients. ${ }^{21}$

It is essential that there is prior communication to the entire team of the presence of patients with suspicion or being positive, so that a thorough anamnesis can be made, focusing on the identification of probable need to assist the NB in breathing at birth or perform neonatal resuscitation maneuvers. In case of clinical stability, the newborn should still be dried with a cord attached to the placenta, receiving the first care in a separate room from the mother or maintaining a distance of two meters. ${ }^{3,21}$

As recommended by the $\mathrm{MH}$, one should not investigate SARS-CoV-2 in asymptomatic NB, even if the mother is a suspect or confirmed case. $9,10 \mathrm{In}$ disagreement, the CDC advises that all children born, regardless of showing signs of infection, should be considered suspect and therefore, perform the RT-PCR with up to 24 hours after birth, from the collection of samples of nasopharynx, oropharynx or nasal swab, considering that the mother has a confirmed or suspected diagnosis for COVID-19. In 
addition, it advises that in case of a negative result or unavailable test, a new examination should be performed 48 hours after birth. ${ }^{21}$ The Sociedade Brasileira de Pediatria (Brazilian Society of Pediatrics) does not comment on screening for SARS-CoV-2 in newborns. 20,21

After immediate care, the stable newborn should proceed from the delivery room or surgical block to the joint housing, the transport of the newborn should take place inside an incubator, regardless of whether the mother is diagnosed for COVID-19 or not. The care in the sector should follow the recommendations of the services, making sure that the infant's contact with the mother is exclusively at the time of breastfeeding, and should thus, follow the routine at home. 20

Women during the pregnancy-puerperal cycle and the NBs are more vulnerable to complications in the presence of the new coronavirus, and it is considered opportune to produce all the knowledge that deals with the recommendations for perinatal care in the context of the COVID-19 pandemic. Studying the issue from the perspective of specific groups becomes more relevant, since Brazil concentrates about $77 \%$ of the world deaths of pregnant women and puerperal by COVID-19.28

This Brazilian study on maternal mortality based on the Sistema Brasileiro de Vigilância da Sindrome do Desconforto Respiratório Agudo (SDRA)(Brazilian Acute Respiratory Distress Syndrome) surveillance database, from the notification of 978 pregnant women and puerperal affected by SARS-CoV-2, showed 24 maternal deaths, with a lethality rate of $12.7 \%$, whereas $48.4 \%$ had at least one comorbidity, $58.9 \%$ admitted to ICU, $53.2 \%$ on invasive ventilation and $29.0 \%$ without ventilatory support. 28 The risk factors described were: obesity, diabetes and cardiovascular disease. The study also showed that the chance of a black woman to die is twice as more than a white woman. ${ }^{28}$

The limitations of this review are understood as the fact that the time elapsed since the beginning of the pandemic is insufficient and the intense flow of information on the subject makes stable recommendations difficult. Most of the retrospective studies and opinion articles increase the risks of information bias.

\section{Final considerations}

Pregnant women represent a population group with particularities, due to the physiological and immunological changes proper to the period, which requires special attention, especially in view of the Brazilian epidemiological scenario.

Analysis of published guidelines, protocols and studies showed that most of the information came from observations of pregnant women in the second and third trimester and from case reports or case series. There is no uniformity among the recommendations.

Prenatal continuity, including teleconsultation, is required. Hospitalization is recommended in specific cases for rigorous monitoring, and pregnancies should be interrupted by cesarean section in cases of maternal or fetal severity. Breastfeeding should be stimulated, as long as maternal care is taken. Early discharge with orientation on continuity of care at home should be considered.

It is expected that new scientific evidence based on studies with more robust methodological designs and analyses will be published, so that perinatal care in the context of the COVID-19 pandemic will be safe and free of complications and unfavorable outcomes for women in the pregnancy-puerperal cycle and for the newborn.

\section{Authors' contribution}

Study design and planning: Oliveira MA, Silva NEF, Pereira JCN, Oliveira MA, Cruz RSBLC. Data collection, analysis and interpretation: Oliveira MA, Silva NEF, Silva SL, Caminha MFC, Paula WKAS, Quirino GS, Oliveira DR, Cruz RSBLC. Elaboration and revision of the manuscript: Oliveira MA, Silva NEF, Pereira JCN, Oliveira MA, Silva SL, Caminha MFC, Paula WKAS, Quirino GS, Oliveira DR, Cruz RSBLC. All authors approved the final version of the article. 


\section{References}

1. Brasil. Ministério da Saúde. Secretaria de Atenção Especializada à Saúde. Departamento de Atenção Hospitalar, Domiciliar e de Urgência. Protocolo de manejo clínico da Covid-19 na Atenção Especializada [recurso eletrônico]. 2020. Disponível em: http://bvsms.saude.gov.br/bvs/publicacoes/manejo_clinico_ covid-19_atencao_especializada.pdf

2. Federação Brasileira de Associações de Ginecologia e Obstetrícia. Protocolo de atendimento no parto, puerpério e abortamento durante pandemia da COVID-19. Atualizado em 27/04/2020. Disponível em: https://www.febrasgo.org.br/pt/covid19/item/1028-protocolo-de-atendimento-no-parto-puerperio-e-abortamentodurante-a-pandemia-da-covid-19.

3. Royal College of Obstetricians \& Gynaecologits (RCOG). Coronavirus (COVID-19) Infection in Pregnancy. Information for healthcare Professionals. 24 July 2020. Disponível em: https://www.rcog.org.uk/globalassets/documents/guidelines/2020-07-24-coronavirus-covid-19-infection-in-pregnancy.pdf

4. The American College of Obstetricians and Gynecologists (ACOG). Novel Coronavirus 2019 (COVID-19). Disponível em: https://www.acog.org/clinical/clinical-guidance/practice-advisory/articles/2020/03/novel-coronavirus2019. Acesso em: 01/07/2020.

5. Osanan GC, Bonomi IB de A, Bacha CA, Laranjeira CLS, Ramos Filho FL, Aguiar RALP de. Coronavirus na gravidez: considerações e recomendações SOGIMIG. 2020 Disponível em: https:/www.sogimig.org.br/wpcontent/uploads/2020/03/Sogimig-

Orienta $\% \mathrm{C} 3 \% \mathrm{~A} 7 \% \mathrm{C} 3 \%$ B5es-sobre-Covid-19-1.pdf

6. Brasil. Ministério da Saúde. Nota técnica $n^{\circ}$ 6/2020COSMU/CGCIVI/DAPES/SAPS/MS- Atenção às gestantes no contexto da infecção sars-cov-2. Ministério da Saúde, Secretaria de Atenção Primária à Saúde. 2020. Disponível em: http://www.enf.ufmg.br/images/SEI_MS__0014128689_-_Nota_Tecnica.pdf.pdf

7. Brasil. Ministério da Saúde. Nota Técnica ${ }^{\circ}$. 7/2020OSMU/CGCIVI/DAPES/SAPS/MS - Atenção às Gestantes no Contexto da Infecção COVID 19 causada pelo novo Coronavírus (Sars-Cov-2). Ministério da Saúde, Secretaria De Atenção Primária à Saúde. 2020. Disponível em: http://www.ans.gov.br/images/stories/gestao_em_saude/par to adequado/SEI_MS - 0014259571 _Nota_Tecnica_3_COSMU.pdf

8. Brasil. Ministério da Saúde. Nota Técnica nº 9/2020OSMU/CGCIVI/DAPES/SAPS/MS - Recomendações para o trabalho de parto, parto, e puerpério durante a pandemia da COVID -19. Ministério da Saúde, Secretaria de Atenção Primária à Saúde, Departamento de Ações Programáticas Estratégicas, Coordenação-Geral de Ciclos da Vida, Coordenação de Saúde das Mulheres. 2020. Disponível em: https://portaldeboaspraticas.iff.fiocruz.br/atencaomulher/covid-19-atencao-as-gestantes.

9. Brasil. Ministério da Saúde. Nota Técnica no 10/2020COCAM/CGCIVI/DAPES/SAPS/MS - Atenção à saúde do recém-nascido no contexto da infecção pelo novo coronavírus (SARS-CoV-2). Ministério da Saúde, Secretaria de Atenção Primária à Saúde. 2020. [acesso 20 ago 2020].
Disponível em: http://189.28.128.100/dab/docs/portaldab/ documentos/notatecnica102020COCAMCGCIVIDAPESSAPSMS_003.pdf

10. Brasil. Ministério da Saúde. Nota técnica $n^{\circ}$ 14/2020COCAM/CGCIVI/DAPES/SAPS/MS- Atenção à saúde do recém-nascido no contexto da infecção pelo novo coronavírus (Sars- CoV-2). Ministério da Saúde, Secretaria de Atenção Primária à Saúde. 2020. Disponível em: https://egestorab.saude.gov.br/image/?file=20200805 N_N otaTecnicaCovidCocam14_3588521282864535759.pdf

11. Whittemore R, Knafl K. The integrative review: updated methodology. J. adv. nurs. [Internet]. 2005; 52(5):546-53.

12. Narang K, Ibirogba ER, Elrefaei A, Trad ATA, Theiler R, Nomura R, Picone O, Kilby M, Escurie TR, Suy A, Carreras E, Tonni G, Ruano R. SARS-CoV-2 in pregnancy: a comprehensive summary of current guidelines. J. Clin. Med. 2020; 9:1521-22.

13. Karimi-Zarchi M, Neamatzadeh H, Dastgheib AS, Abbasi H, Mirjalili SR, Behforouz A, Ferdosian F, Bahrami R. Vertical transmission of coronavirus disease 19 (COVID19) from infected pregnant mothers to neonates: a review. Fetal Pediatr Pathol. 2020; 39 (3): 246-50.

14. Vivanti AJ, Vauloup-Fellous C, Prevot S, Zupan V, Suffee C, Do Cao J, Benachi A, De Luca D. Transplacental transmission of SARS-CoV-2 Infection. Nature Communications. 2020; 3572: 1-7.

15. Wang S, Guo L, Chen L, Liu W, Cao Y, Zhang J, Feng L. A case report of neonatal 2019 coronavirus disease in china. Clin Infect Dis. 2020; 71(15):853-57.

16. Zhang Z, Wang C, Gao CC. Neonatal coronavirus expert confirmed at 30 hours of birth: vertical transmission from mother to infant. [cited 2020 Aug 10]. Available from: http://www.cnr.cn/hubei/yuanchuang/20200205/ t20200205 524961963.

17. IMIP (Instituto de Medicina Integral Prof. Fernando Figueira). Protocolo assistencial para atendimento de casos suspeitos ou confirmados de Covid-19 em gestantes e puérperas no Centro de Atenção a Mulher (CAM). Recife; 2020. Disponível em: http://server.informazione.com.br/imip/ arquivos/noticia/PROTOCOLOCOVID19 CAM 15abr2020 13h.pdf

18. ISEA (Instituto de Saúde Elpídio de Almeida). Protocolo de atendimento de pacientes com COVID-19 (infecção suspeita ou confirmada). Campina Grande: ISEA; 2020.

19. CDC (Centers for Disease Control and Prevention). Considerations for inpatient obstetric healthcare settings. Disponível em: https://www.cdc.gov/coronavirus/2019ncov/hcp/inpatient-obstetric-healthcare-guidance.html.

20. Sociedade Brasileira de Pediatria. Aleitamento Materno em tempos de COVID-19 - recomendações na maternidade e após a alta. Disponível em: https://www.sbp.com.br/ fileadmin/user_upload/22467f-NA_-

AleitMat tempos_COVID-19-na matern e apos alta.pdf

21. Sociedade Brasileira de Pediatria. Recomendações para Assistência ao Recém-Nascido na sala de parto de mãe com COVID-19 suspeita ou confirmada (Atualização 2). Disponível em: https://www.sbp.com.br/fileadmin/ 
user upload/22499c-NA-

Assist_RN_SalaParto_de_mae_com_COVID-19.pdf

22. Berthelot N, Lemieux R, Garon-Bissonnette J, DrouinMaziade C, Martel É, Maziade M. Uptrend in distress an psychiatric symptomatology in pregnant women during the COVID-19 pandemic. Acta Obstet and Gynecol Scand. 2020; 99: 848-55.

23. Wu Y, Zhang C, Liu H, Duan C, Li C, Fan J, et al. Perinatal depressive and anxiety symptoms of pregnant women along with COVID-19 outbreak in China. Am J Obstet Gynecol. 2020; 223 (2): 240.e1-240.e9..

24. Dphil MK, Bunch K, Vousden N, Morris E, Simpson N, Gale C, O'Brien P, Quigley M, Brocklehurst P, Kurinczuk JJ. Characteristics and outcomes of pregnant women hospitalised with confirmed SARS-CoV-2 infection in the UK: a national cohort study using the UK Obstetric Surveillance System (UKOSS). BMJ; 2020; 369: 1-7.

25. Martínez-Perez O, Vouga M, Cruzmelguizo S, Acebal LF, Panchaud A, Muñoz-Chápuli M, Baud D. Association between mode of delivery among pregnant women with COVID-19 and maternal and neonatal outcomes in Spain. JAMA; 2020; 324 (3): 296-9.

26. CDC (Centers for Disease Control and Prevention). Care for breastfeeding women: interim guidance on breastfeeding and breast milk feeds in the context of COVID-19. Disponível em: https://www.cdc.gov/coronavirus/2019ncov/hcp/care-for-breastfeeding-women.html.

27. CDC (Centers for Disease Control and Prevention). Evaluation and management considerations for neonates at risk for COVID-19. Disponível em: https://www.cdc.gov/coronavirus/2019-ncov/hcp/caringfor-newborns.html.

28. Takemoto MLS, Menezes MO, Andreucci CB, Knobel R, Sousa L, Katz L, Fonseca EB, Nakamura-Pereira M, Magalhães CG, Diniz CSG, Melo ASO, Amorim MMR. Clinical characteristics and risk factors for mortality in obstetric patients with severe COVID-19 in Brazil: a surveillance database analysis. BJOG; 2020.

Received on September 28, 2020

Approved on December 7, 2020 